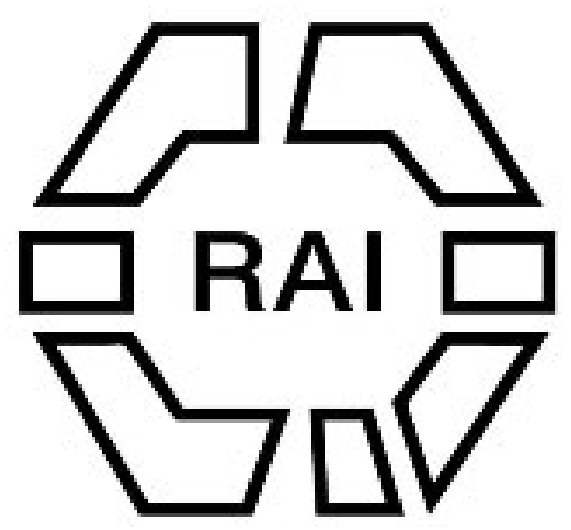

Exhibition of Anthropometric Instruments.

Author(s): Horace Darwin

Source: The Journal of the Anthropological Institute of Great Britain and Ireland, Vol. 16 (1887), pp. 9-11

Published by: Royal Anthropological Institute of Great Britain and Ireland

Stable URL: http://www.jstor.org/stable/2841733

Accessed: 15/06/2014 07:40

Your use of the JSTOR archive indicates your acceptance of the Terms \& Conditions of Use, available at http://www.jstor.org/page/info/about/policies/terms.jsp

JSTOR is a not-for-profit service that helps scholars, researchers, and students discover, use, and build upon a wide range of content in a trusted digital archive. We use information technology and tools to increase productivity and facilitate new forms of scholarship. For more information about JSTOR, please contact support@jstor.org. 
test of acuteness of vision, unless it called upon the person tested to see the separateness of two or more objects, such as spots, which were separated from each other by intervals equal to their own diameters. The separateness of such objects did not become visible until their retinal images were so large that the image of the interval between them completely covered a single retinal element. Until this condition was fuifilled, two or more dots, although their position might be discoverable as a matter of luminosity, as in the familiar case of double stars, discoverable as single ones by tho naked eye, could not be said to be either objects or tests of vision, properly so called. He hoped that the labours of the Committee on the subject were not concluded, and that they would be able to arrive at some simple and practical test composed of two or more dots or other objects.

\section{Exhibition of ANThropometric Instruments.}

\section{By Horace Darwin, Esq., M.A.}

Mr. Horace Darwin apologised for the incomplete state of the apparatus exhibited. He first showed an instrument for testing the keenness in distinguishing small differences in the pitch of a musical note. An organ pipe giving about the middle $\mathrm{C}$ was blown by a bellows. Its pitch could be altered by a known amount by changing its length. Constancy of air pressure is of considerable importance, and could easily be obtained with a more perfect bellows.

The next instrument shown was a chronograph made according to the design of the President, Mr. F. Galton, for measuring the quickness with which a person can press a lever after a sound signal is given. A wooden rod is supported at its upper end by a detent, and can be released at will. The rod then falls freely in space passing through a hole in a fixed diaphragm. A weight in the form of a ring, larger than the hole in the diaphragm, rests on a collar near the top of the rod. Thus, after rod and weight together have fallen a definite distance, the weight is caught by the diaphragm and makes the signal sound, while the rod still continues to fall. On hearing the signal sound the person to be tested presses down a lever, thereby releasing a spring clamp which grips the falling rod firmly. The interval of time between the signal sound and this operation is measured by the space the rod has fallen through, and is read at once in hundredths of a second from graduations on the rod itself.

The third instrument shown-designed at the suggestion of the President-was for measuring the relative sensitiveness of the eye to various colours in different persons. An object, such as a card, on which numbers are printed in diamond type, is fixed 
against the side of a box and is viewed through a small hole in the opposite side of the box. The various colours are obtained by placing pieces of coloured glass in front of the hole. The diffused light falling on the card passes through an adjustable aperture and through a translucent screen at the end of the box The illumination of the card can be varied by the adjustable aperture, and is proportional to its area.

To use the instrument, the person looks at the card through a piece of coloured glass, moves the adjustment till he can only just read the numbers, and notes the area from a scale. He does the same with any other coloured glasses. Now if daylight be used for illuminating the apparatus, the numbers obtained from the scale obviously depend on the brightness of the day. It is therefore necessary either to use a standard illumination, or if daylight be used, to reduce the numbers to ratios. In this case it would be convenient to consider the observation with one particular colour as 100 and to reduce all other observations so as to maintain the original ratio.

The following instruments of Mr. Galton's design were also exhibited :

Apparatus for testing the judgment of the eye in estimating squareness, also for testing the power of dividing a line into two equal parts.

Head-spanners, for measuring length and breadth of the head and the height of the head above the plane passing through the holes in the ears and the ridge of the frontal bone above the eyes, to which reference has already been made.

\section{Discussion.}

Mr. Brudenell Carter inquired whether Mr. Darwin was acquainted with Professor Förster's instrument for the purpose of testing the acuteness of light perception. It consisted of a box, the interior of which contained a series of broad stripes, alternately black and white, as objects, and was illuminated either by lamplight or daylight through a square opening which could be increased in area from one to sixteen hundred square millimetres. This instrument was useful in ascertaining the soundness or otherwise of the retina in cases in which vision was too much impaired to be testerd in the ordinary way.

Mr. JoSEPH JACOBS remarked that in all experiments with instruments for measuring sensation, variations are likely to arise owing to subjective differences of nerve fatigue, \&c., in the subject at different times. Thus the same man might appear to have a limit of clear vision at 21 inches on one occasion, and at 24 at another. No inprovements in instruments could obviate this source of error, which could be only eliminated in each individual by taking the average of a series of observations between different individuals by taking the observations under the same conditions. He would 
observe that the instrument for measuring quickness of hearing did not directly achieve its purpose, for a certain appreciable time ("reaction time" the physiologists call it) elapsed between the hearing and the pressing down of the lever which arrested the fall of the rod. There was variation in "reaction time" as well as in quickness of hearing. Mr. Galton's instrument was only intended to measure the sum of these variables. To ascertain the quickness of hearing the "reaction time," to be ascertained by the meihod of Exner or other means, would have to be subtracted.

Dr. RAYNER said that he had an instrument for taking measurements of the skull and head, which, in addition to the graduated horizontal bar, with two sliding graduated vertical limbs, had on each of these last a smooth pointed traveller projecting one inch and reversible, so that interior measurements could be taken.

Professor Flower, Mr. C. Roberts, and Professor Thane, also took part in the discussion.

The following Paper was then read by the author:

\section{The Cephalid Index.}

By J. G. Garson, M.D., F.Z.S., M.A.I., Mem. Corresp. Etm. Soc. d'Anthrop. de Paris. Lecturer on Comparative Anatomy, Charing Cross Hospital; Royal College of Surgeons of England.

THE cephalic index expresses in percentage the relative proportion which the breadth of the skull bears to the length, and is thus an exact method of indicating the general form of the skull in those two relations. Depending as it does on the measurement of length and breadth, it is at once evident that if a skull is to give the same index in the hands of different observers these diameters must always be measured in exactly the same way. Skulls being termed dolichocephalic, mesaticephalic or brachycephalic according as the cephalic index is low, medium, or high, it is likewise necessary, in order that these terms may always indicate the same form of skull, that each should have a certain fixed limit, otherwise a skull which is dolichocephalic according to one nomenclature may be mesaticephalic by another system, and vice versâ. Till lately great differences in measuring the length and breadth, and of classifying the cephalic index have existed among anthropologists. With the advancement of anthropological science these differences are disappearing, and the time has come when we may hope to have an uniform system of measurement and of nomenclature. To obtain this great efforts are being made by 